\title{
The Oxide Coarsening and its Influence on Recrystallization in a Mechanically Alloyed Fe-base ODS alloy
}

\author{
C. CAPDEVILA
}

\begin{abstract}
Analytical Transmission Electron Microscopy has been used to determine whether yttria particles readily coarsen in oxide dispersion strengthened (ODS) ferritic stainless alloy (PM2000), in an attempt to contribute to a model which explains the directionality of the microstructure observed when this material undergoes recrystallization under isothermal conditions. Likewise, the role of $\mathrm{Al}_{2} \mathrm{O}_{3}$ particles in the recrystallization processes of alumina enriched PM2000 alloy has been studied via the addition of 1 wt.- $\% \mathrm{Al}_{2} \mathrm{O}_{3}$ particles as dispersoids. A carbon extraction replica technique was used to show that no coarsening of the yttria dispersion occurred even under exaggerated heat treatment at $1380{ }^{\circ} \mathrm{C}$ for 1 hour. By contrast, a significant ripening of alumina particles occurred apparently without influence on the recrystallization processes.
\end{abstract}

C. CAPDEVILA, Tenure Scientist, is in the Department of Physical Metallurgy, Centro Nacional de Investigaciones Metalúrgicas (CENIM), Consejo Superior de Investigaciones Científicas (CSIC), Avda. Gregorio del Amo, 8, 28040 Madrid, Spain. E-mail: ccm@cenim.csic.es. Tlf: +34-915538900, Fax: +34915347425 www.cenim.csic.es 


\section{INTRODUCTION}

The development of iron based alloys as an alternative for the more traditional nickel based superalloys for some components in power plant gas turbine is now well underway. The advantages of using a ferritic stainless alloy instead of a nickel based alloy in medium temperature applications are readily apparent: not only an iron based alloy would be considerably cheaper than the nickel counterpart, but a significant improvement could be expected in mechanical properties. These range from a superior strength to weight ratio, to a higher melting temperature, which would be expected to give substantially higher creep resistance, to a lower thermal expansion coefficient, which under cyclic heating would rise to less thermal stresses development.

An iron based alloy currently being considered for such an application is an $\mathrm{Fe}-\mathrm{Cr}-\mathrm{Al}$ alloy, mechanically alloyed with yttrium oxide. The oxide dispersion is included to confer greater strength on the alloy, causing substantial directionality in the microstructure upon recrystallization of the alloy.

The development of a high directional microstructure has been shown to be extremely important in nickel based alloys which are currently used in this application. Wilcox and Claver ${ }^{[1]}$ showed that this type of structure greatly enhanced creep rupture properties, by having fewer grain boundaries along which easy diffusion would be possible in the direction of elongated grains. In order to attain such microstructure in nickel based alloys (which have been oxide dispersion strengthened) it is necessary to subject the material to a zone annealing heat treatment; isothermal annealing merely produces an equiaxed structure. It has been shown by Schaffer et al ${ }^{[2]}$ that in a nickel based alloy, such as Incoloy MA6000, the oxide dispersion did not coarsen at temperatures up to $850{ }^{\circ} \mathrm{C}$, but that some coarsening did occur when the material was treated at $1100{ }^{\circ} \mathrm{C}$ for 1000 hours. This coarsening was via an interface controlled mechanism, involving Ostwald ripening behavior. 
Coarsening of this type has been shown to occur much more readily in other systems. It has been shown by Bhattacharyya and Russell ${ }^{[3]}$, for example, that silica will readily coarsen in a copper matrix at temperatures below $1000{ }^{\circ} \mathrm{C}$ after only a 24 hour treatment. It had been suggested that such coarsening behavior may well occur in the ferritic steel — yttrium oxide system, and that this could be responsible for triggering the highly directional microstructure, observed even under isothermal recrystallization heat treatments. The aim of this work was to deduce whether or not yttria readily coarsen in a ferritic matrix.

Furthermore, experimental evidence also suggests that there are subsidiary microstructural aspects which contribute to limitations in the creep performance of these alloys, since it has been found that alumina particles may play a role in creep deformation as either source or sink sites for vacancies ${ }^{[4-5]}$. Bands of axially aligned, coarse $\mathrm{Al}_{2} \mathrm{O}_{3}$ particles originating from the feedstock powders which can end up clustered on longitudinal secondary recrystallized grain boundaries, and hence that coarse $\mathrm{Al}_{2} \mathrm{O}_{3}$ particles are nucleation sites for creep cavities on longitudinal boundaries ${ }^{[6]}$. However, less clearly understood is the role that these $\mathrm{Al}_{2} \mathrm{O}_{3}$ particles may play through Zener pinning in developing directional microstructures. This is the second goal of this work, which was achieved through the analysis of the nature and size of the dispersoids in two different batches of PM2000.

\section{MATERIAL AND EXPERIMENTAL PROCEDURE}

The material used for the purpose of the work was provided by PLANSEE GmbH. PM2000 is yttria dispersion strengthened alloy containing aluminum and chromium for oxidation and corrosion resistance; it is produced using mechanical alloying in a high-energy ball mill. After alloying, the powder is consolidated by hot isostatic pressing and then formed into bars by hot extrusion. In the case discussed here, the ingot material had an outer diameter of $54.1 \mathrm{~mm}$. 
The extruded bar was then further hot-rolled, and finally, cold rolled to $17.3 \mathrm{~mm}$ diameter. Figure 1 shows the processing history used from ball milling to the final fine-grained bar. The material shows an exceptional oxidation and corrosion resistance, due to the formation of a surface alumina scale. This scale has been shown to provide good resistance in hydrogen methane atmospheres and also in sulphidizing atmospheres ${ }^{[7-10]}$.

\section{(FIGURE 1)}

The nature and size of the dispersoids in two different batches of PM2000 it is analyzed in this work. One of them (Alloy A) is a pure PM2000, with 0.5 wt-\% of yttria. The other one (Alloy B) is PM2000 base material but 1wt-\% alumina enriched material with only $0.1 \mathrm{wt}-\%$ yttria (Table I). The amount of $\mathrm{Ti}$ and $\mathrm{O}$ does not correspond to solid solution elements, but includes the oxide too

Table I. Chemical composition (wt. \%).

\begin{tabular}{ccccccccc}
\hline Alloy & $\mathrm{Al}_{2} \mathrm{O}_{3}$ & $\mathrm{Cr}$ & $\mathrm{Ti}$ & $\mathrm{O}$ & $\mathrm{Y}_{2} \mathrm{O}_{3}$ & $\mathrm{Al}$ & $\mathrm{C}$ & $\mathrm{Fe}$ \\
\hline $\mathrm{A}$ & - & 19.4 & 0.48 & 0.24 & 0.5 & 5.38 & 0.014 & Balance \\
& & & & & & & & \\
\hline B & 1.0 & 19.4 & 0.48 & 0.24 & 0.1 & 5.38 & 0.014 & Balance
\end{tabular}

The material is known to undergo recrystallization at temperatures between $1100-1300{ }^{\circ} \mathrm{C}$. In this sense, samples of Alloys A and B were annealed for an hour at 1075, 1100, 1200, 1300 and $1380{ }^{\circ} \mathrm{C}$ (melting point $1483{ }^{\circ} \mathrm{C}$ ). Optical micrographs were taken, and hardness of these samples measured. The etchant used to reveal the microstructure was a solution containing $2 \mathrm{~g}$ $\mathrm{CuCl}_{2}, 40 \mathrm{ml} \mathrm{HCl}, 40$ - $80 \mathrm{ml}$ ethanol (Kalling Reagent). 
Since a statistical analysis of very small sized particles was required, it was decided to produce carbon extraction replicas. Extraction replicas allow examining relatively large areas of a sample in the transmission electron microscope compared to thin foils. Carbon replicas were prepared according to Fukami 'two step replica method' ${ }^{[11]}$. Samples were polished in the usual way and then lightly etched with Kalling reagent. A small amount of methyl acetate was dropped and spread on the surface of the specimen. Before the volatilization of the solvent, a cellulose acetate film was laid over the specimen. After a few minutes the film was peeled off from the specimen. Subsequently, to avoid the curling of the material, it was kept for about 30 minutes in an air oven heated to $80^{\circ} \mathrm{C}$. Then, the film was put into a high vacuum chamber to perform carbon deposition. Finally, the cellulose acetate layer was dissolved in a sequence of acetone baths. A copper mesh was used to support carbon replicas which were examined in a JEOL JEM-200 CX transmission electron microscope operating at $200 \mathrm{keV}$. The ripening processes was analyzed measuring the sizes of 700 particles from micrographs of as-received and annealed samples in alloys A and B. Image analysis procedures allowed quantify the particle size distribution in both alloys. Two measurements of each selected particle were made, mutually perpendicular to each other. Areas of different samples were chosen at random and all particles in that small area were measured. This produce a representative distribution of particles sizes.

\section{RESULTS AND DISCUSSION}

\section{A. Particle size distribution}

Figures 2 and 3 show the particles identified, as well as the raw data sorted as a frequency distribution showing the number of particles having sizes between certain values. It is clear 
that the majority of the particles are yttria in Alloy A, meanwhile aluminum garnets are predominant in Alloy B. Previous works ${ }^{[12]}$ revealed a strong alignment of oxide particles after mechanical alloying processes. Since confirm such alignment in the as-received condition was not the aim of this work, transmission electron micrographs from transversal section of the sample were used to obtain the data presented in these figures Nevertheless, the results for alumina enriched material (Alloy B) are quite different for those for Alloy A. The density of particles is substantially higher in Alloy B. The size distribution graphs show an average diameter of $19 \mathrm{~nm}$ for Alloy A (Fig. 2(b)) vs. $29 \mathrm{~nm}$ for alloy B (Fig. 3(b)), although most of the particles (over 50\%) fall in the $40-60 \mathrm{~nm}$ size range. This could be interpreted as the existence of particles with fairly different sizes in Alloy B.

(FIGURE 2)

(FIGURE 3)

(FIGURE 4)

(FIGURE 5)

On the other hand, Figs. 4 and 5 show the nature and sizes of particles after annealing at $1380{ }^{\circ} \mathrm{C}$ for 1 hour in both Alloy A and B. In this case, the observation was performed on longitudinal section of the samples instead of transversal one, in order to check that the severe annealing performed do not affect the alignment of the particles in rolling direction. A comparison between Figs. 2 and 4 clearly shows that no coarsening of yttria particles in Alloy A occurred, even under exaggerated heat treatment., whereas the comparison between Figs. 3 
and 5 shows a binomial distribution in particles sizes, which allowed to concluded that some of the particles coarsen very fast in Alloy B (Fig. 5) after annealing at $1380{ }^{\circ} \mathrm{C}$. Likewise, some agglomeration of oxide particles, probably due to inhomogeneities of MA processing, has been detected (Fig. 6).

In general all the particles were more or less spherical; very few particles having a high aspect ratio were observed. The particles tended to align along directions parallel to the initial rolling direction; this is clearly visible in the TEM micrograph of the replicas shown in Fig. 4 and Fig. 5. This effect was still pronounced even after recrystallization had occurred. A possible explanation for the lack of coarsening of oxide particles of Alloy A may lie in a low solubility of yttria in ferritic matrix, low interface mobility and/or a low diffusivity of yttria in the matrix. One or more of these factors added together could easily explain the experimental results. No quantitative data were available to conclusively prove this.

\section{(FIGURE 6)}

The higher diffusivity of aluminum in the matrix and the concentration of aluminum in solid solution (up to $6 \mathrm{wt} . \%$, see Table I) could explain the coarsening of the alumina particles in this superalloy. This coarsening is detrimental form mechanical properties point of view since coarse particles do not pin the dislocations in their movement during plastic deformation, decreasing therefore the strength of the material, specially for those product designed for high temperature service, i.e. biomass heat exchanger tubes ${ }^{[13]}$. Likewise, the coarsening of the oxide particles could also affect the recrystallization processes, which is the subject of the next section. 


\section{B. Recrystallization behavior}

Hardness results for annealed samples are presented in Fig. 7. It is clear that the drop in hardness values is consequence of the starting of recrystallization. Thus, the minimum recrystallization temperature is lightly lower in Alloy B as compare to Alloy A $\left(1075{ }^{\circ} \mathrm{C}\right.$ rather than $1100{ }^{\circ} \mathrm{C}$ ). This recrystallization temperature has been checked through metallographic observations. As it can be observed in Fig. 8, only a few small recrystallized grains appear in the microstructure (see arrows). Likewise, it is clear from Fig. 7 that complete recrystallization takes place between 1100 and $1380{ }^{\circ} \mathrm{C}$ since the hardness values recorded at such temperature are similar to those for fully recrystallized material.

(FIGURE 7)

\section{(FIGURE 8)}

Figure 9 and 10 show partial recrystallized microstructure in Alloy A and B for 1200 and $1300{ }^{\circ} \mathrm{C}$, respectively. Some islands of dark areas inside a lighter matrix are detected. Such dark areas decrease in number as annealing temperature increases. In order to clarify the nature of theses dark and light areas, microhardness measurements were performed (Fig. 11). Light areas in the optical micrographs had a lower hardness than the dark areas, as it is shown in Fig. 11. This suggests that the dark areas correspond to islands of unrecrystallized material embedded in a recrystallized matrix (Figure 12). This is consistent with experimental evidence shown in TEM micrographs of Fig. 13. Nevertheless, light areas of annealed samples at intermediate temperatures were not as soft as the fully recrystallized material (Fig. 11). This is possibly due to the fact that unrecrystallized regions may be lying underneath these areas. 
(FIGURE 9)

(FIGURE 10)

(FIGURE 11)

(FIGURE 12)

(FIGURE 13)

(FIGURE 14)

Samples annealed at $1300{ }^{\circ} \mathrm{C}$, and in a major extent samples treated at $1380{ }^{\circ} \mathrm{C}$, were similar to samples annealed at $1200{ }^{\circ} \mathrm{C}$ except that the proportion of recrystallized to unrecrystallized regions had increased. The fine structured areas were again slightly more coarse, leading to a reduction in hardness.

Figure 14 shows fully recrystallized, directional microstructure, with large elongated grains, in the direction of the initial extrusion and rolling for sample of Alloy B annealed at $1380{ }^{\circ} \mathrm{C}$. The dark areas of these samples are now due to preferential etching of certain crystallographic plane orientations: they do not exhibit any fine structure, and are fully recrystallized areas. The microhardness of light and dark areas is approximately the same. However, fully recrystallization has not been achieved for Alloy A at $1380{ }^{\circ} \mathrm{C}$ for 1 hour. Such microstructure is obtained after isothermal heat treatment at $1390{ }^{\circ} \mathrm{C}$ for 1 hour. 
So far, it could be concluded that both alloys present a recrystallized microstructure formed by elongated grains. This anisotropy in grain orientation is consistent with hardness values measured in fully recrystallized microstructure. Meanwhile hardness values are almost the same between transversal and longitudinal sections of the sample in the as-received condition (i.e. $\mathrm{HV}=441 \pm 5$ in longitudinal section and $\mathrm{HV}=443 \pm 5$ in transversal section in alloy $\mathrm{B}$ ), there are however significant different values between both sections in the fully recrystallize condition (i.e. $\mathrm{HV}=251 \pm 5$ in longitudinal section and $H V=271 \pm 8$ in transversal section in alloy B), which is consequence of the directional microstructure produced during recrystallization

No particles coarsening has taken place to any significant extent after annealing at $1380^{\circ} \mathrm{C}$ for 1 hour in Alloy A. Longer annealing times may well reveal some coarsening of the particles, but this is not particularly relevant in this case, because this very slow coarsening cannot be responsible for triggering directional recrystallization.

On the other hand, significant coarsening of the particles occurs during annealing in Alloy B, and a directional microstructure in a very similar temperature range is also obtained. This could indicate that the size of the particles is not responsible for nucleation of recrystallization, and hence, triggering such process.

\section{Model for Recrystallization}

So far it has been shown that particle coarsening could not be responsible for promoting the start of recrystallization, what other explanation is there for such a phenomenon? As it is shown in Fig. 15(a), the as-received microstructure contains significant directionality, with grains elongated parallel to the rolling direction due to rolling processes, i.e. a microstructure 
similar to that observed in conventional cold rolled ferritic steel but in a much finer scale. It is in this stage where oxide particles are aligned in longitudinal direction.

(FIGURE 15)

As it can be observed in Fig. 15(b), just before the nucleation of recrystallization starts, the elongated microstructure evolves to a more equiaxed one, but sub micrometric in size. In this stage, the nucleation of the recrystallize grain takes place by the bowing of grain boundaries. With the sub-micrometer grain size of mechanically alloyed metals, the grain junctions themselves act as severe pinning lines for grain boundary bowing ${ }^{[12-14]}$. The activation energy for the nucleation of recrystallization thus becomes very large, giving the high recrystallization temperatures characteristic of this material. However, this activation energy drops if a few grains happen to be slightly larger, i.e. if the grains are not uniform in size ${ }^{[15-}$ 16]. It follows that a heterogeneous distribution of strain with its associated non-uniform distortions of the sub-micron cold-worked microstructure, makes the nucleation recrystallization easier. This is precisely what is found. Assuming that recrystallization takes place by means of a bowing mechanism, a non-uniform microstructure corresponding to inhomogeneous deformation assists nucleation by making available some grains which are sufficiently large to permit easy bowing. This would lead to a greater nucleation rate and hence a finer recrystallized grain size. By contrast, a uniform fine grain structure would find it more difficult to recrystallize and hence the few successful nuclei would develop into a coarse grained microstructure; this is exactly the case for the bars studied here.

Once the grain has nucleated, is then supposed that abnormal grain growth takes place, whereby one already large grain grows even larger at expenses of neighboring smaller grains (Fig. 8). The driving force for this change is a chemical potential difference across curved 
grain boundary ${ }^{[17]}$. This abnormal grain growth will still, however, be subjected to the anisotropic distribution of the particles. The particles hinder boundary motion more effectively in the radial direction of the bar. Author and co-workers reported the large difference, about four orders of magnitude, in the measured interfacial velocities as a function of orientation relative to the extrusion direction in a PM2000 tube ${ }^{[18]}$. The boundary propagates by the motion of ledges in the radial direction. The ledges develop not because of an orientation-dependent interfacial energy but because of the anisotropic distribution of yttria particles. In this sense, when two such growing grains meet, their boundary will tend to align along the direction of yttria particles. The resultant microstructure is the one experimentally observed.

\section{CONCLUSIONS}

The results presented in this work allow us to conclude that coarsening of yttria did not occur, even when the material was subjected to exaggerated heat treatment (average size of $18 \mathrm{~nm}$ in diameter). The results for alumina enriched material (Alloy B) are quite different. The density of particles is higher in this material than in Alloy A. Longitudinal section revealed a welldefined particle orientation in the extrusion direction. The size distribution graph shows an average diameter of $29 \mathrm{~nm}$. After exaggerated annealing at $1380{ }^{\circ} \mathrm{C}$ it could be observed a binomial distribution in particles sizes, which allowed to concluded that some of the particles coarsen very fast as compare with the others. Likewise, agglomeration of oxide particles has been detected in Alloy B, probably due to inhomogeneity in particle distribution during MA processing.

Since no significant differences were found in recrystallization processes between Alloy A and Alloy B, it could be concluded that the appreciable coarsening of the alumina particles 
presented in Alloy B does not seem to affect the elongated grain structure characteristic of the recrystallized microstructure. Thus particles ripening cannot be responsible for triggering directional recrystallization and abnormal grain growth in Alloy A and B. The elongated recrystallized grain structure is heavily influenced by the alignment of yttria particles, which is brought about as a consequence of the rolling process.

Finally, a model based in the bowing of grain boundaries of the sub-micrometer grain structure has been used to explain the recrystallization process of the material studied. The grain junctions act themselves as severe pinning lines for grain boundary bowing. The activation energy for the nucleation of recrystallization thus becomes very large, giving the high recrystallization temperatures and the coarse recrystallized grains characteristic of this material.

\section{ACKNOWLEDGEMENTS}

Professor H.K.D.H. Bhadeshia from University of Cambridge is acknowledged for fruitful discussions. PLANSEE GmbH is acknowledged for the supply of the material. A.R Jones and Y.L Cheng from University of Liverpool are also acknowledged for the useful discussions.

\section{REFERENCES}

[1] B.A. Wilcox and A.H. Clauer: Acta Metall, 1972, vol. 20, pp. 743-57.

[2] G.B Schaffer, M.H. Loretto, R.E Smallman and J.W. Brooks: Acta Metall., 1989, vol. 37, pp. 2551-58. 
[3] S.K. Bhattacharyya, K.C. Russell: Metall. Trans. A , 1976, vol. 7A, pp. 453-62.

[4] D.M. Jaeger and A.R. Jones: Proc. of Materials for Advanced Power Engineering, D. Coutsouradis, E. Bachelet, R. Brnetaud, P. Esslinger, J. Ewald, I. Kvernes, Y. Lindblom, D. B. Meadowcroft, V. Regis, R.B. Scarlin, K. Schneider, R. Singer (eds), Kluwer Academic Press, Liege, 1994, pp. 1515-21.

[5] D.M. Jaeger and A.R. Jones: Proc. of Materials for Advanced Power Engineering, D. Coutsouradis, E. Bachelet, R. Brnetaud, P. Esslinger, J. Ewald, I. Kvernes, Y. Lindblom, D. B. Meadowcroft, V. Regis, R.B. Scarlin, K. Schneider, R. Singer (eds), Kluwer Academic Press, Liege, 1994, pp. 1507-14.

[6] D. Sporer and K. Lempenauer: Proc. 13th International Plansee Seminar, Metallwerk Plansee, Reutte, Austria, 1993, pp.796-801.

[7] H. D. Hedrich: New materials by mechanical alloying techniques, E.D. Artz and L. Schultz (eds), Kluwer Academic Press, Germany, 1986, pp. 217-224.

[8] G. P. DeGaudenzi, F. Uberti, F. Bregani and G. P. Toledo: Materials for Advanced Power Engineering Part II, D. Coutsouradis, E. Bachelet, R. Brnetaud, P. Esslinger, J. Ewald, I. Kvernes, Y. Lindblom, D. B. Meadowcroft, V. Regis, R.B. Scarlin, K. Schneider, R. Singer (eds), Kluwer Academic Publishers, The Netherlands, 1994, pp. 1563-70.

[9] M. J. Fleetwood: Mater. Sci. Technol., 1986, vol. 2, pp. 1176-82. 
[10] J.D. Whittenberger: Metall Trans A, 1979, vol. 10A, pp. 1285-95.

[11] A. Fukami: Specimen Preparation Techniques for Electron Microscopy, Jeol News, Tokio, 1967, pp. 5-7.

[12] C. Capdevila, U. Miller, H. Jelenak and H.K.D.H. Bhadeshia: Mater. Sci. Eng A, 2001, vol. A316, 2001, pp. 161-65.

[13] U. Miller, A. Fleming, R. Oberg, A. Jones, P. Brondsted and H.K.D.H. Bhadeshia: Development of Torsional Grain Structures to Improve Biaxial Creep Performance of Fe-based ODS Alloy Tubing for Biomass Power Plant, BRITE EURAM III project, Project nº BE 97-4949, European Community Publications, Brussels, 2002.

[14] H. K. D. H. Bhadeshia: Mater. Sci. Eng. A, 1997, vol. A223, pp. 64-77.

[15] C. Capdevila and H.K.D.H. Bhadeshia: Adv. Eng. Mater., 2001, vol. 3, pp. 647-56.

[16] K.Murakami, K. Mino, H. Harada and H.K.D.H. Bhadeshia: Metall. Trans. A, 1994, vol. 25A, pp. 625-53.

[17] J.W. Martin, R.D. Doherty and B. Cantor: Stability of microstructures in metallic systems, Cambridge University Press, Cambridge, 1997, pp. 221-228. 
[18] C. Capdevila, Y.L. Chen, A.R. Jones and H.K.D.H. Bhadeshia: ISIJ Int., 2003, vol. 43, pp. $777-83$. 
Table I. Chemical composition (wt. \%).

\begin{tabular}{ccccccccc}
\hline Alloy & $\mathrm{Al}_{2} \mathrm{O}_{3}$ & $\mathrm{Cr}$ & $\mathrm{Ti}$ & $\mathrm{O}$ & $\mathrm{Y}_{2} \mathrm{O}_{3}$ & $\mathrm{Al}$ & $\mathrm{C}$ & $\mathrm{Fe}$ \\
\hline $\mathrm{A}$ & - & 19.4 & 0.48 & 0.24 & 0.5 & 5.38 & 0.014 & Balance \\
& & & & & & & & \\
\hline $\mathrm{B}$ & 1.0 & 19.4 & 0.48 & 0.24 & 0.1 & 5.38 & 0.014 & Balance \\
\hline
\end{tabular}




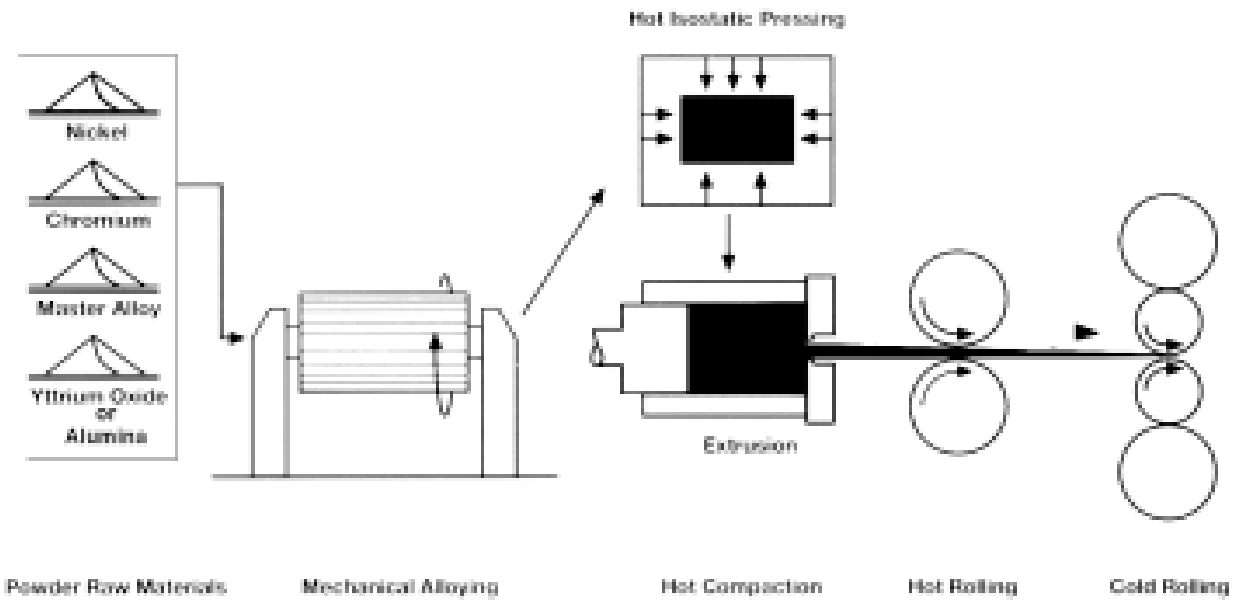

Figure 1. Scheme of the Plansee alloy PM2000 bar processing. 

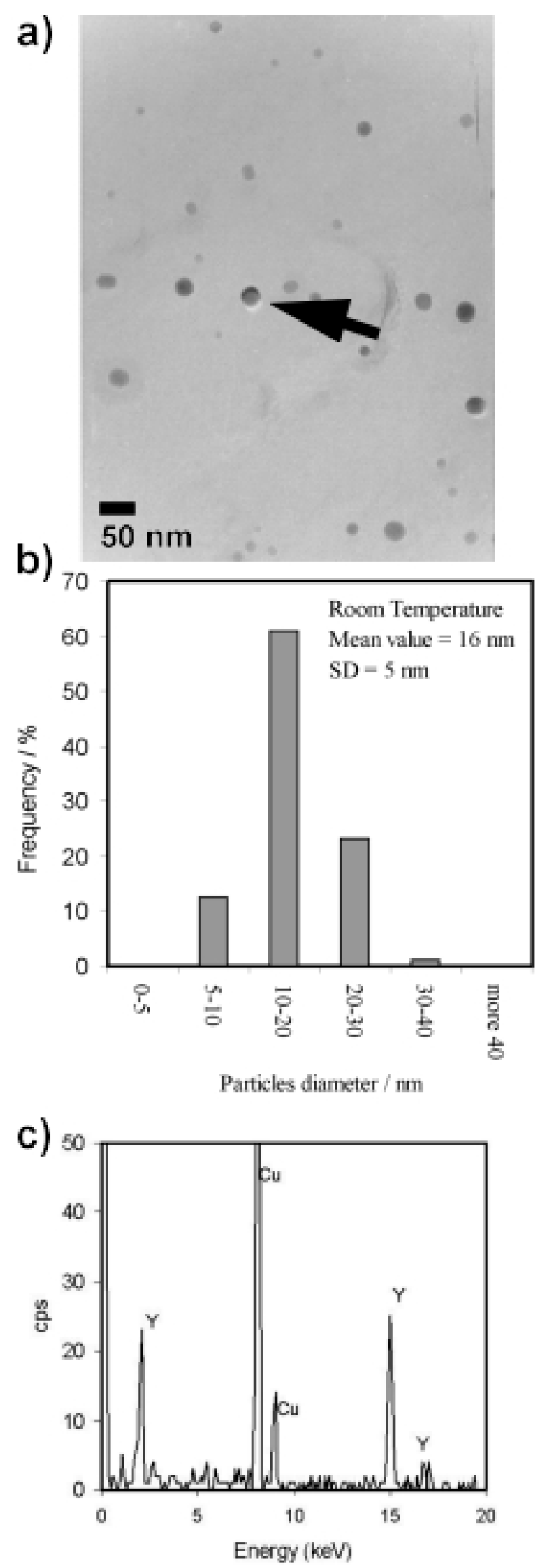

Figure 2. Alloy A in as-received condition: a) Particle orientation, b) distribution sizes, and c) nature. 

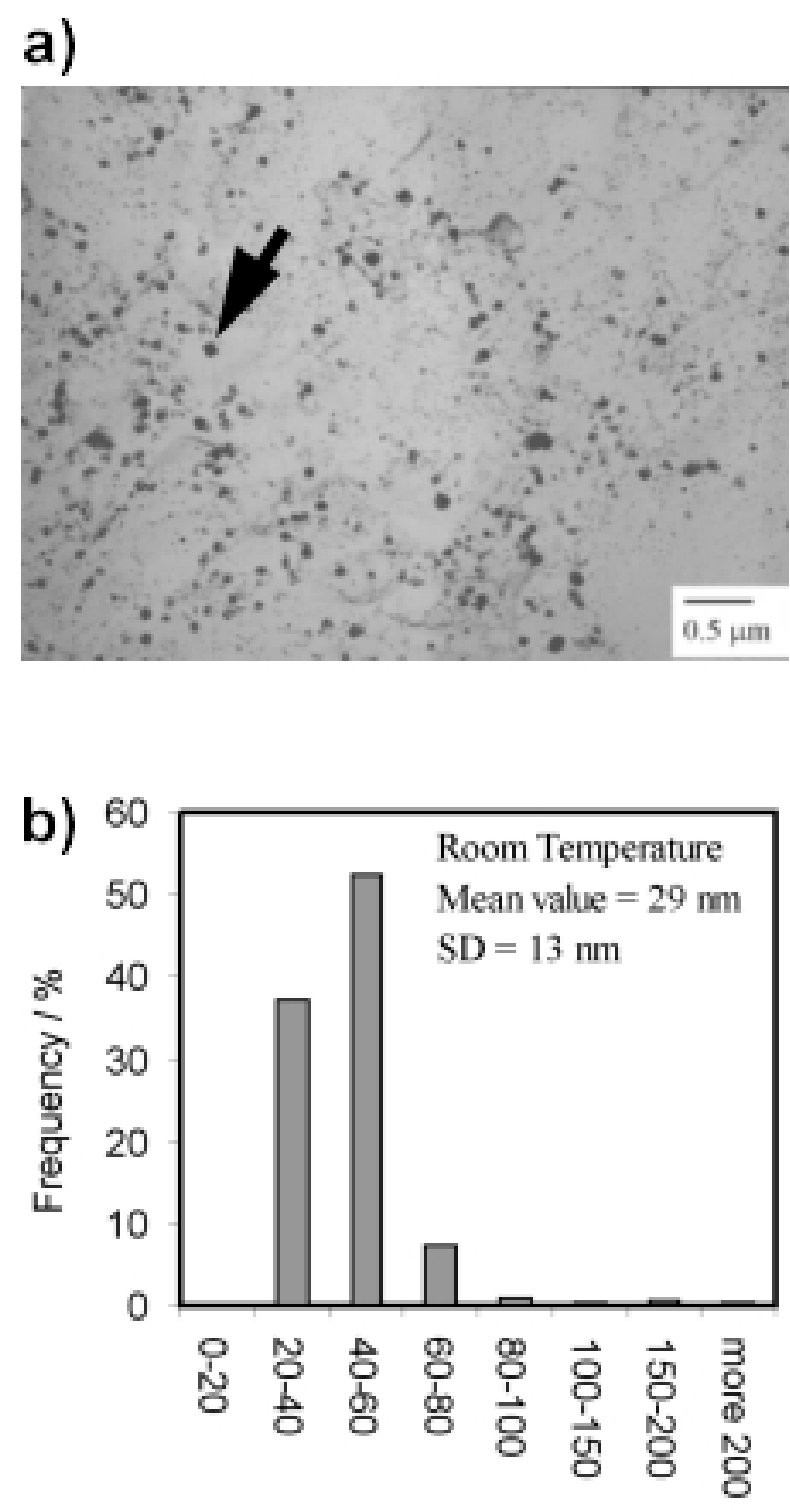

Particles diameter / $\mathrm{nm}$

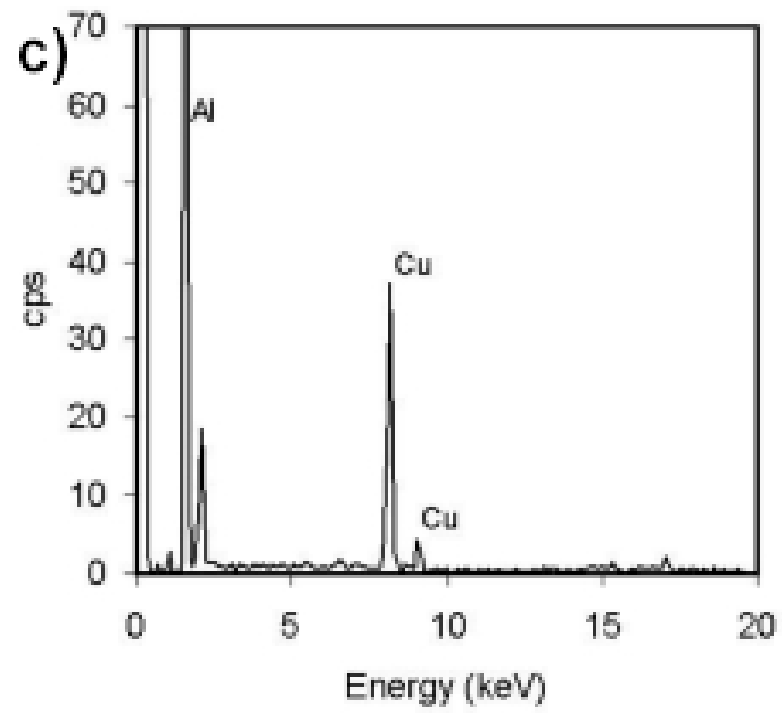

Figure 3. Alloy B in as-received condition: a) Particle orientation, b) distribution sizes, and c) nature. 

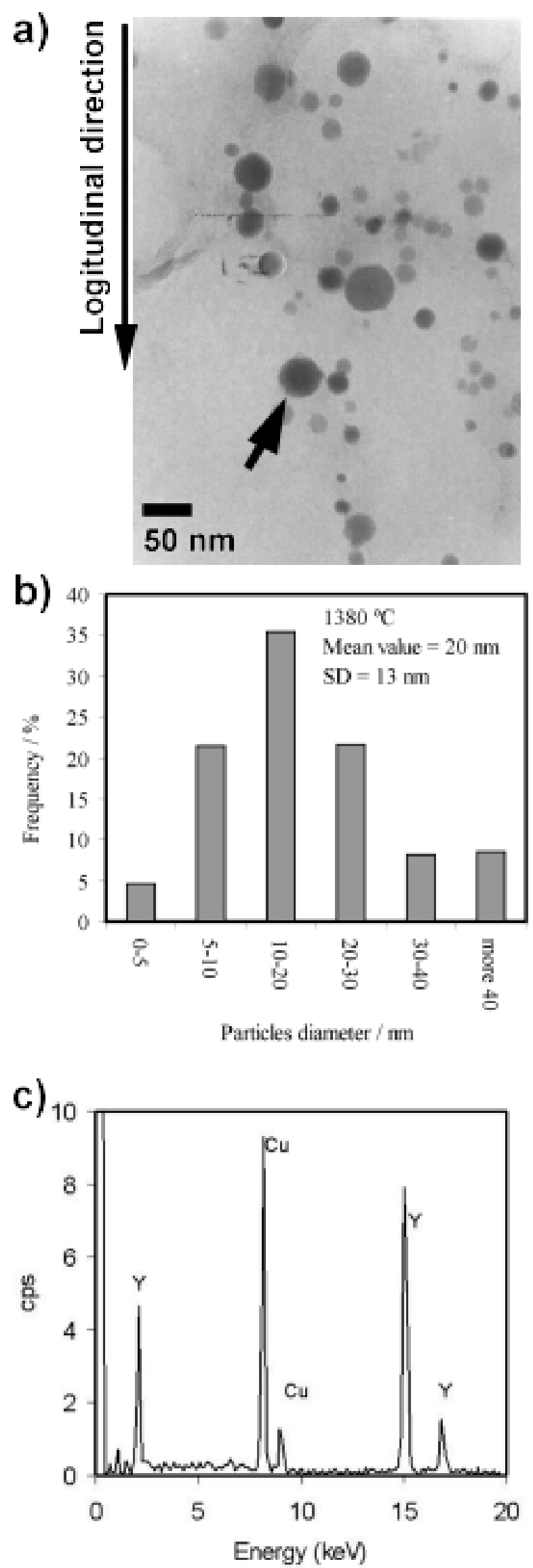

Figure 4. Alloy A after isothermal heat treatment at $1380{ }^{\circ} \mathrm{C}$ for 1 hour: a) Particle orientation, b) distribution sizes, and c) nature. 

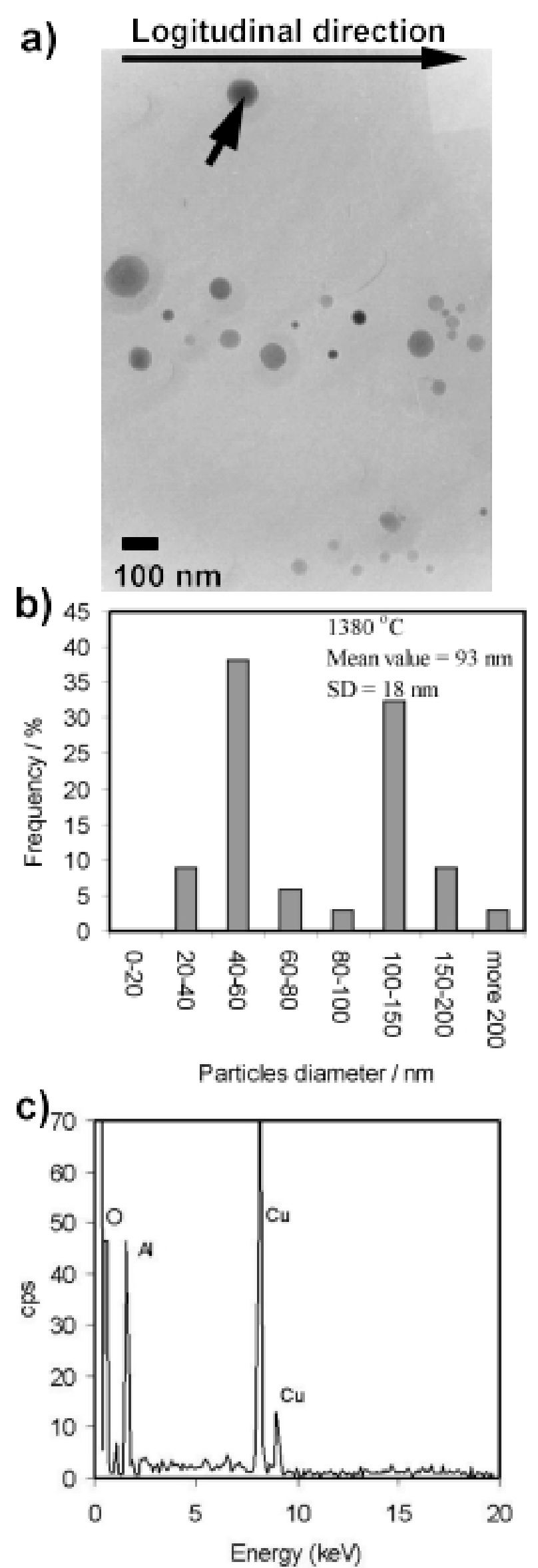

Figure 5. Alloy B after isothermal heat treatment at $1380{ }^{\circ} \mathrm{C}$ for 1 hour: a) Particle orientation, b) distribution sizes, and c) nature. 



Figure 6. Agglomeration of oxide particles in Alloy B. 


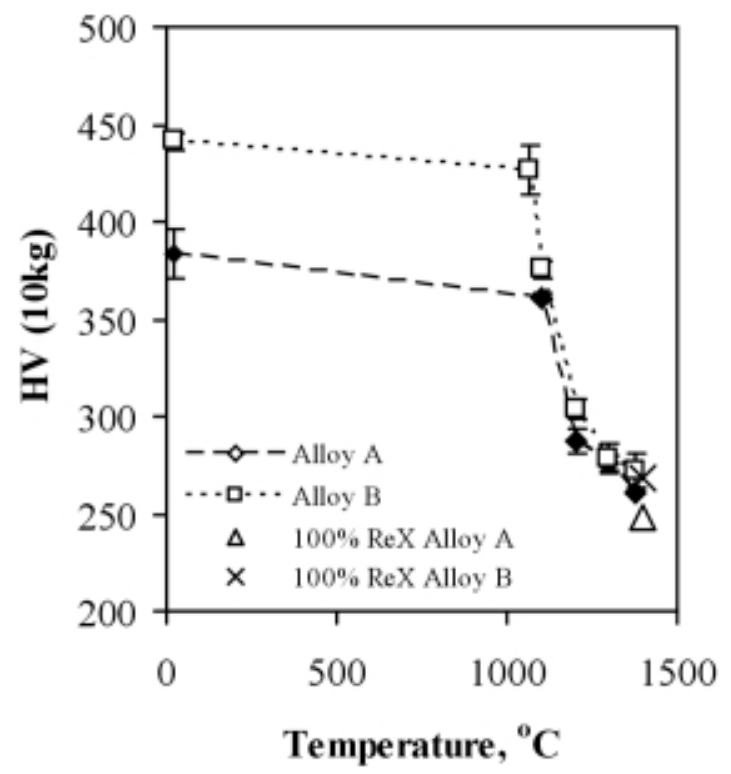

Figure 7. Vickers hardness measurements for both alloys as a function of annealing temperature in (a) longitudinal section, and (b) transversal section. 

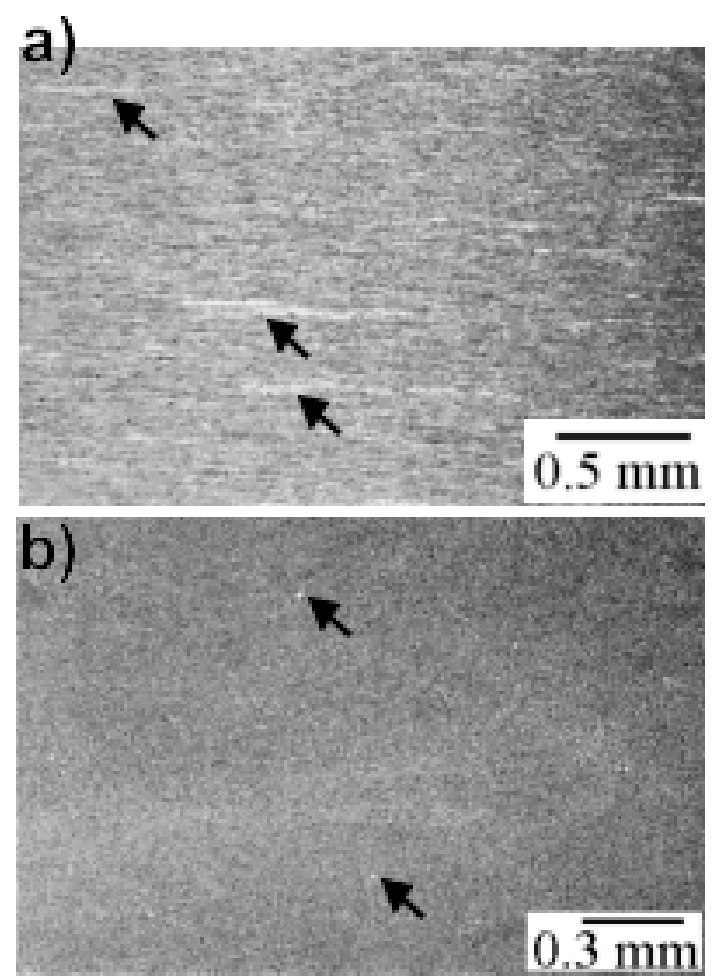

Figure 8. Recrystallization microstructure of (a) longitudinally sectioned sample annealed at $1100{ }^{\circ} \mathrm{C}$ for alloy $\mathrm{A}$, and (b) transversally sectioned sample annealed at $1075{ }^{\circ} \mathrm{C}$ for alloy B. 

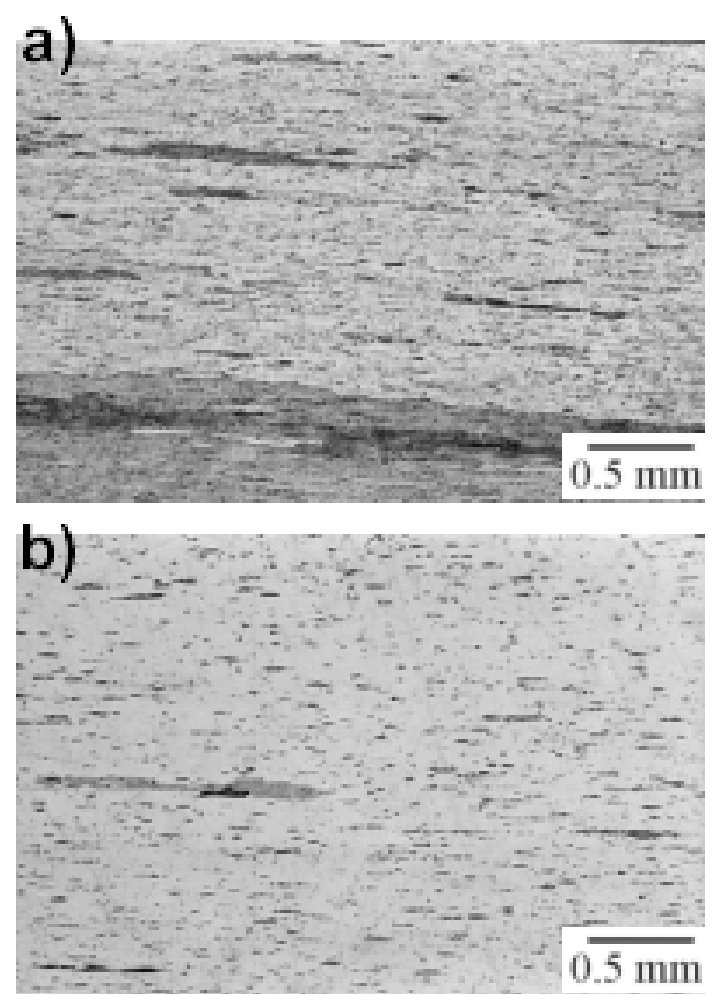

Figure 9. Longitudinal section of recrystallized microstructure at $1200{ }^{\circ} \mathrm{C}$ for $1 \mathrm{~h}$ in (a) alloy A and (b) Alloy B. 

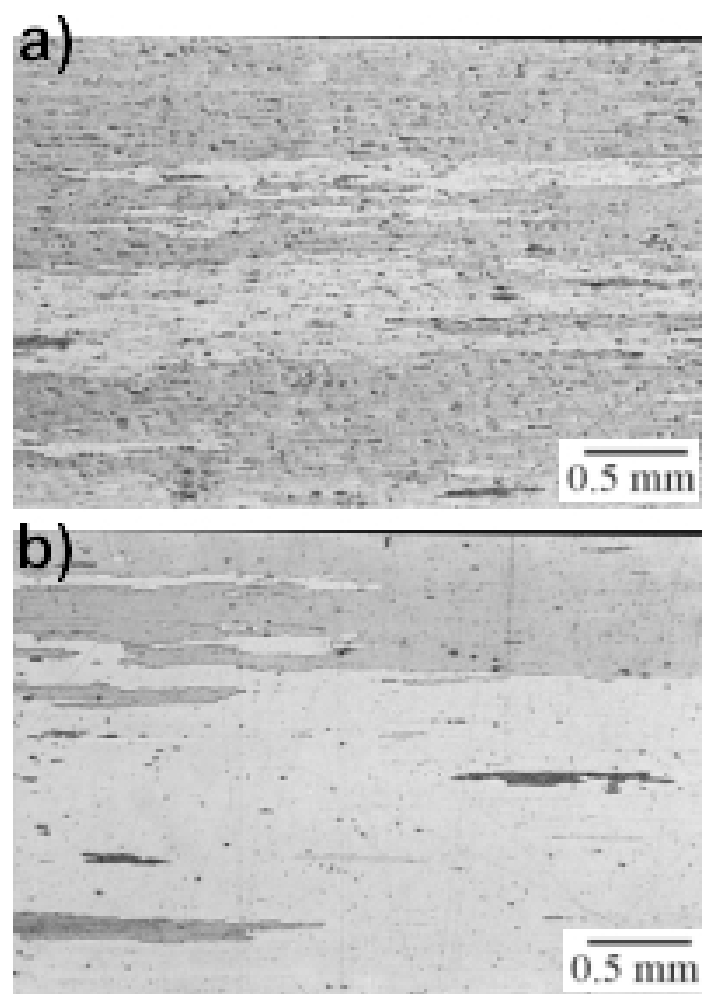

Figure 10. Longitudinal section of recrystallized microstructure at $1300{ }^{\circ} \mathrm{C}$ for 1 hour in (a) alloy A and (b) Alloy B. 

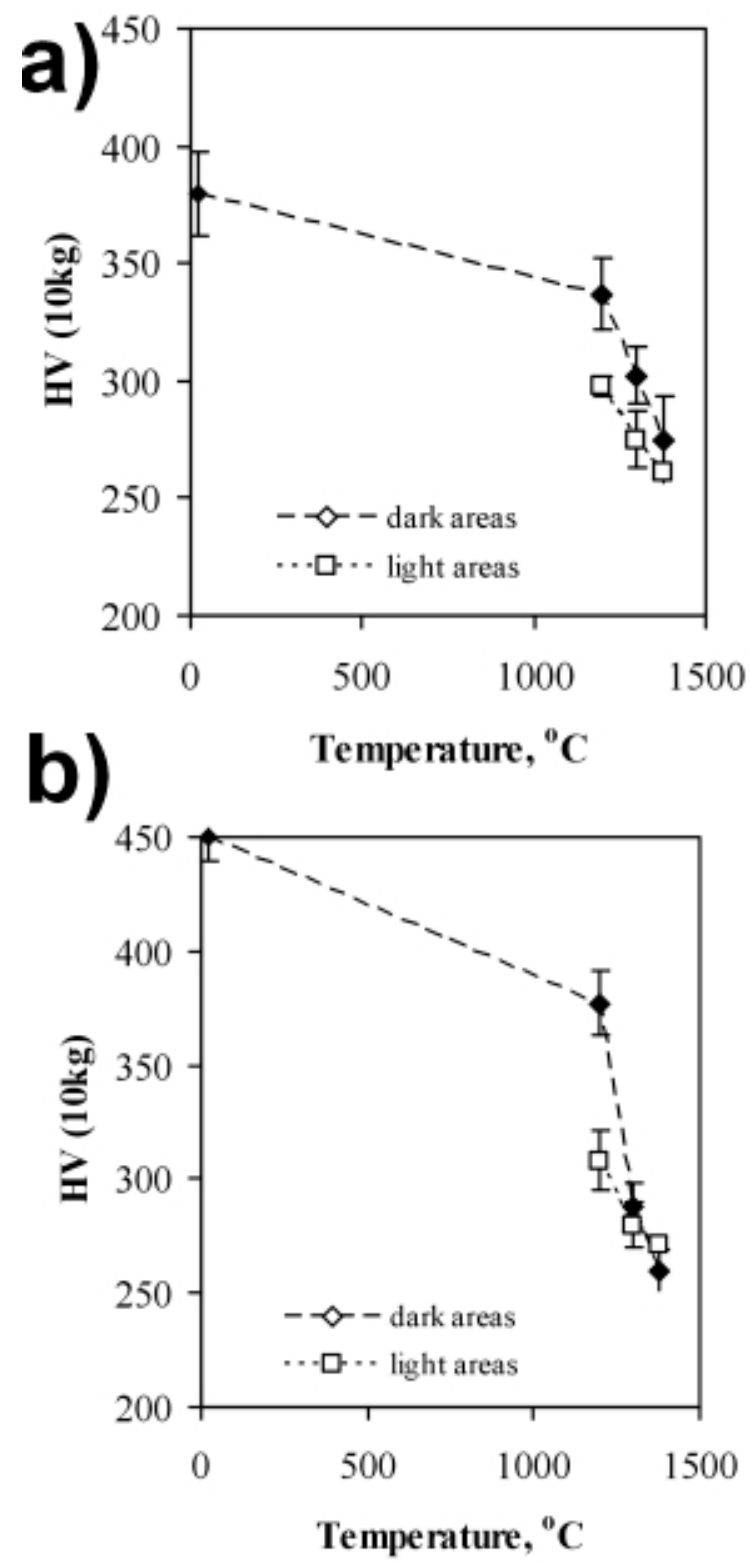

Figure 11. Microhardness measurements as a function of temperature for (a) alloy A, and (b) alloy B, both in longitudinal direction. 


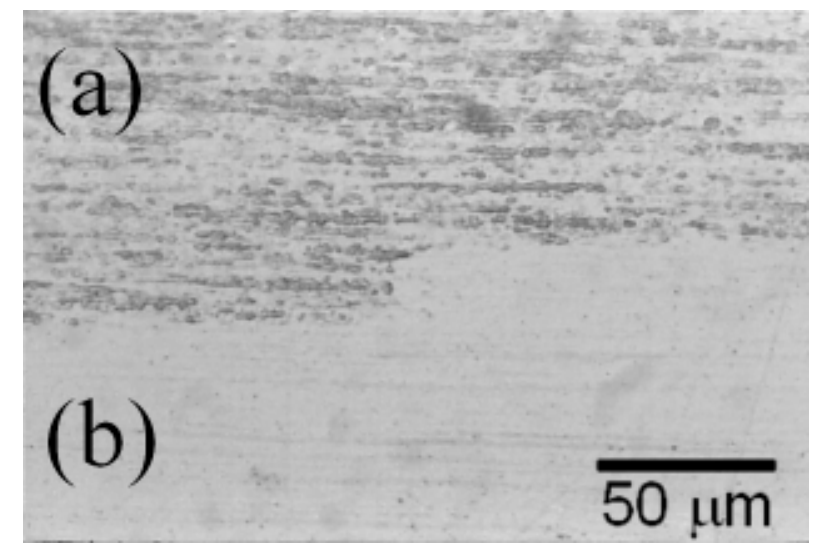

Figure 12. Detail of the dark (a) and light areas (b) in Alloy A at $1200{ }^{\circ} \mathrm{C}$. Dark areas correspond to fine grained material, and light areas to recrystallized material. 

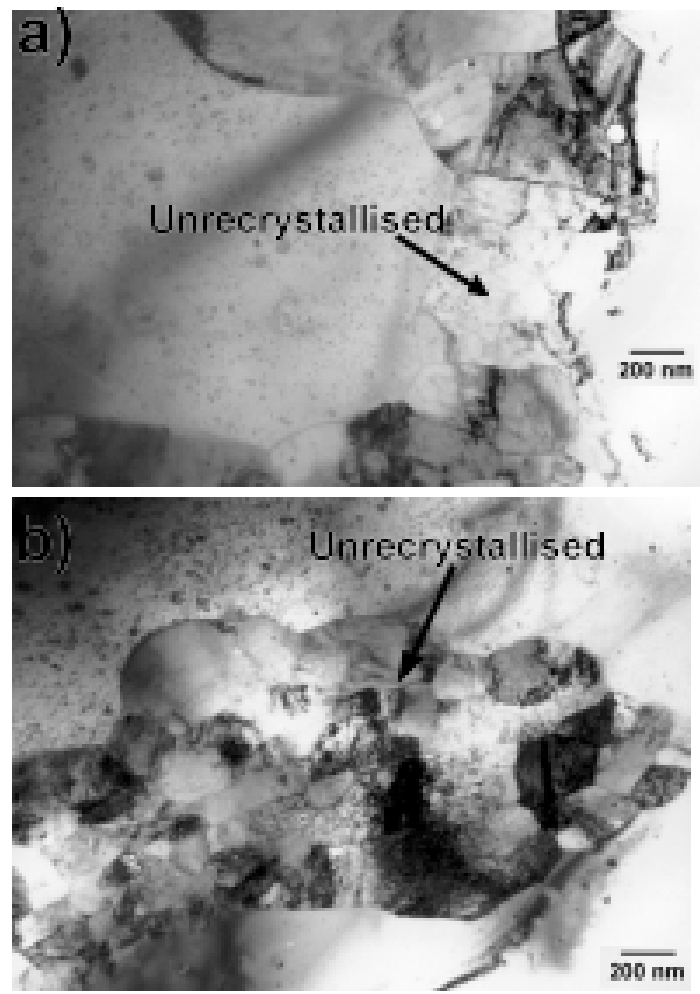

Figure 13. Fine grained dark areas of recrystallized microstructure at $1200{ }^{\circ} \mathrm{C}$ for 1 hour in (b) alloy A and (b) Alloy B. 

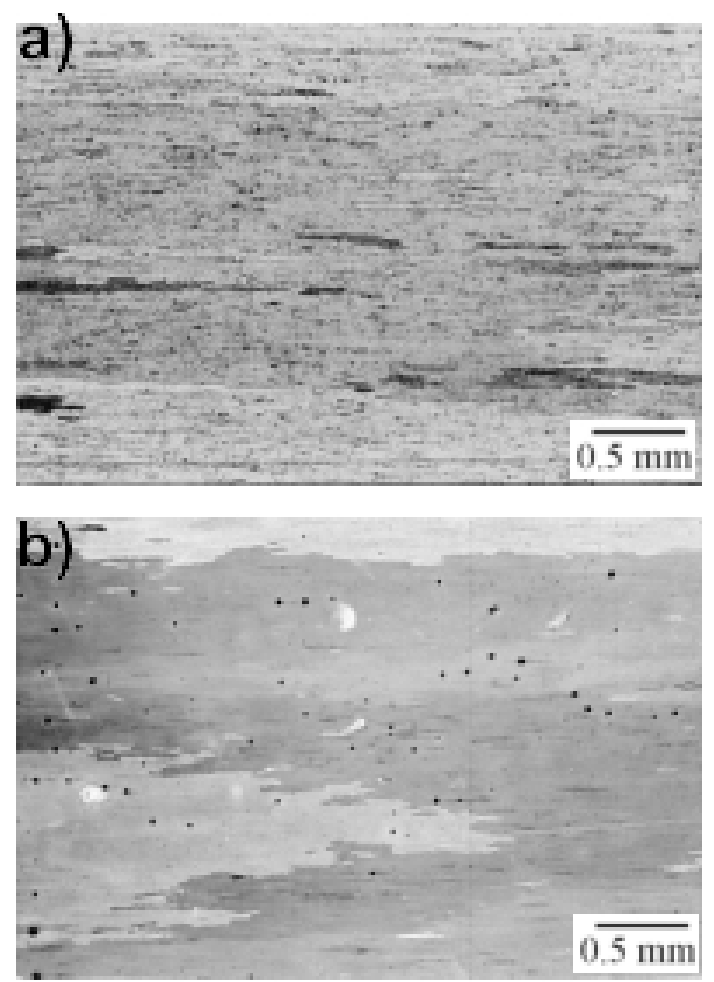

Figure 14. Longitudinal section of recrystallized microstructure at $1380{ }^{\circ} \mathrm{C}$ for 1 hour in (a) alloy A and (b) Alloy B 


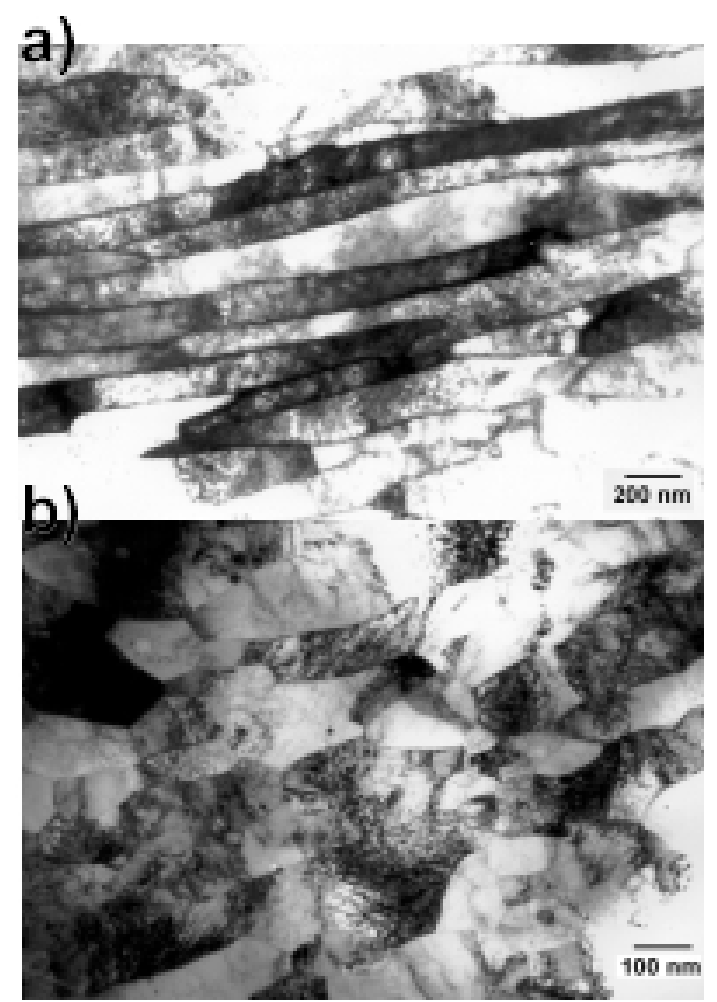

Figure 15. Unrecrystallized material in (a) as-received condition, and (b) annealed at $1100{ }^{\circ} \mathrm{C}$ for 1 hour in Alloy A. Both are longitudinal sections. 